\title{
Structural properties of methoxy derivatives of benzyl bromide, determined from powder X-ray diffraction data
}

\author{
Zhigang Pan, Eugene Y. Cheung, and Kenneth D. M. Harris ${ }^{a)}$ \\ School of Chemistry, Cardiff University, Main Building, Park Place, Cardiff CF10 3AT, Wales, \\ United Kingdom \\ Edwin C. Constable and Catherine E. Housecroft \\ Department of Chemistry, University of Basel, Spitalstrasse 51, 4056 Basel, Switzerland
}

(Received 28 June 2005; accepted 12 October 2005)

\begin{abstract}
Structure determination of 3,5-dimethoxybenzyl bromide and 3,4,5-trimethoxybenzyl bromide has been carried out from laboratory powder X-ray diffraction data using the direct-space Genetic Algorithm technique for structure solution followed by Rietveld refinement. These two compounds are of interest for their potential use as building blocks for the synthesis of dendritic materials. Although the two molecules differ only in the presence/absence of the methoxy group at the 4-position of the aromatic ring, the structural properties of the two materials are significantly different. (C) 2005 International Centre for Diffraction Data. [DOI: 10.1154/1.2135789]
\end{abstract}

Key words: organic materials, structure solution, genetic algorithm, direct-space techniques

\section{INTRODUCTION}

The field of powder diffraction has seen many significant advances over the last 40 years or so, and in this special issue of Powder Diffraction dedicated to Daniel Louër, it is appropriate to recognize the wide-ranging contributions that he has made to this field, which encompass new fundamental aspects of powder diffraction methodology as well as the application of powder diffraction techniques to tackle novel and important structural problems (Louër and Louër, 1972; Louër, 1988; Boultif and Louër, 1991; Louër, 1996; Langford and Louër, 1996; Louër, 1998; McCusker et al., 1999; Langford et al., 2000; Giovannini et al., 2001a; 2001b; Louër, 2003; Boultif and Louër, 2004). As a result, many practitioners in the powder diffraction field have benefited from the contributions that Professor Louër and his research group have made to this field over the years.

Much of our own current research is focused on structure determination of organic molecular solids from powder diffraction data, and the present paper is focused in this area. Within the last decade or so, new opportunities have opened up for carrying out complete structure determination of organic molecular solids directly from powder diffraction data (Harris and Tremayne, 1996; Harris et al., 2001; Chernyshev, 2001; Harris and Cheung, 2004; Altomare et al., 2004; Favre-Nicolin and Černý, 2004; Shankland et al., 2004), particularly through the development of the direct-space strategy for structure solution (Harris et al., 1994). Recent methodological advances in this field are such that organic molecular crystal structures of moderate complexity can now be determined fairly routinely by this approach. Nevertheless, structure determination from powder diffraction data is not a black-box technique, and considerable care must be taken to ensure the correctness of the structure obtained.

This paper reports the structure determination of two organic molecular materials: 3,5-dimethoxybenzyl bromide [denoted 3,5-DMBB; Figure 1(a)] and 3,4,5-trimeth-

\footnotetext{
${ }^{\text {a) }}$ Author to whom correspondence should be addressed. Electronic mail: HarrisKDM@cardiff.ac.uk
}

oxybenzyl bromide [denoted 3,4,5-TMBB; Figure 1(b)], carried out from powder X-ray diffraction data using the directspace genetic algorithm technique (Kariuki et al., 1997; Harris et al., 1998; Habershon et al., 2003) for structure solution followed by Rietveld refinement (McCusker et al., 1999; Rietveld, 1969; Young, 1993). Both of these materials are of interest in our research on dendritic materials as they serve as precursors for some of the families of dendrimers of interest. The crystal structure of a related molecule 3,5dimethoxybenzyl alcohol, which is also of interest as a dendrimer precursor, has also been determined from powder X-ray diffraction data (Pan et al., 2004). Such organic molecular solids are particularly amenable to structure determination using the direct-space strategy for structure solution because reliable information on specific aspects of molecular geometry (e.g., standard bond lengths and bond angles) is already known, and therefore the structure solution calcula-

(a)

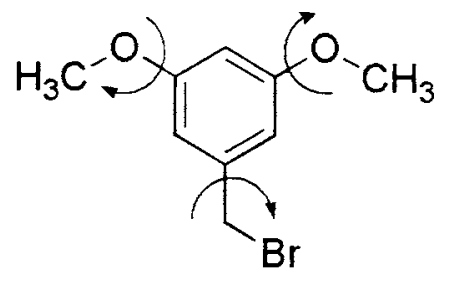

(b)

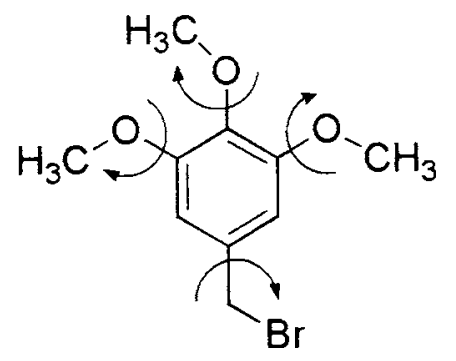

Figure 1. Molecular structures of (a) 3,5-DMBB and (b) 3,4,5-TMBB. The arrows indicate the variable torsion angles in the structure solution calculation from powder X-ray diffraction data. 

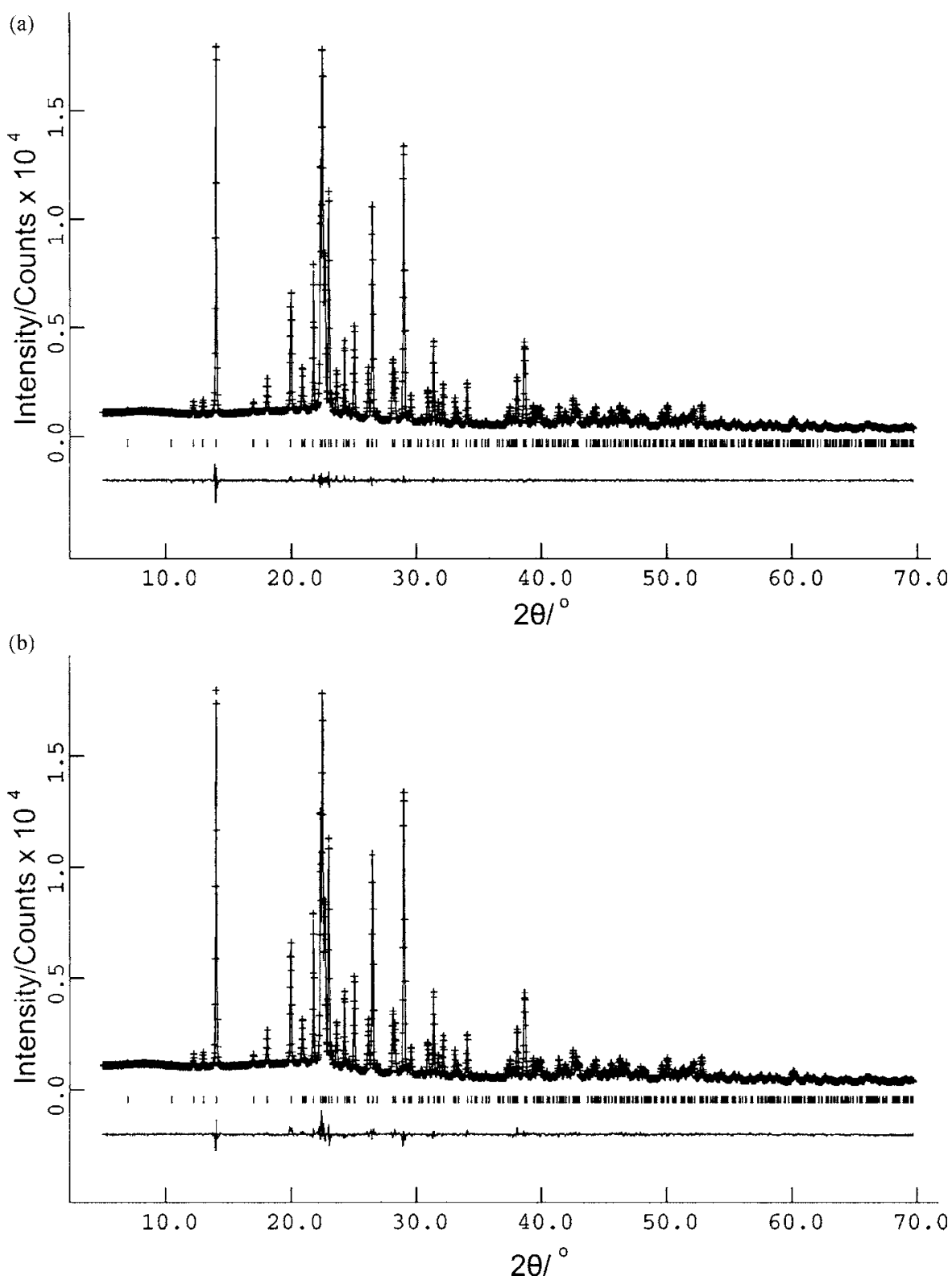

Figure 2. (a) Le Bail fit of the powder X-ray diffraction pattern for 3,5DMBB, showing the experimental powder X-ray diffraction pattern $(+$ marks), calculated powder X-ray diffraction pattern (solid line), and difference profile (lower line). The tick marks indicate reflection positions. (b) Final Rietveld refinement for 3,5DMBB, showing the experimental powder X-ray diffraction pattern $(+$ marks), calculated powder X-ray diffraction pattern (solid line), and difference profile (lower line). The tick marks indicate reflection positions.

tion requires only to establish the position and orientation of the molecule in the asymmetric unit, and the molecular conformation.

\section{BACKGROUND TO STRUCTURE DETERMINATION OF ORGANIC MOLECULAR SOLIDS FROM POWDER X-RAY DIFFRACTION DATA}

The stages involved in crystal structure determination from powder X-ray diffraction data are (i) unit cell determination [which, in the work presented here, has been carried out using the DICVOL program (Louër and Louër, 1972; Boultif and Louër, 1991; 2004) developed in the group of Daniel Louër]; (ii) pattern-decomposition/profile-fitting [which is commonly carried out using the techniques developed by Pawley (1981) and Le Bail et al., (1988)]; (iii) structure solution; and (iv) structure refinement. The aim of structure solution is to obtain an initial approximation to the structure, using knowledge of the unit cell and space group determined in the first two stages, but starting with no knowledge of the actual arrangement of atoms or molecules within the unit cell. If the structure solution is a sufficiently good approximation to the true structure, a good quality structure can then be obtained by structure refinement, which is generally carried out using the Rietveld profile refinement technique.

Among recent developments in techniques for carrying out structure solution from powder X-ray diffraction data, the direct-space strategy is particularly suitable in the case of organic molecular materials. In the direct-space strategy, trial crystal structures are generated in direct space, and the quality of each trial structure is assessed by direct comparison between the powder X-ray diffraction pattern calculated for the trial structure and the experimental powder X-ray diffraction pattern (in our work, this comparison is carried out using the weighted powder profile $R$-factor $R_{\text {wp }}$, which takes peak overlap implicitly into consideration). In the present paper, 
TABLE I. Fractional coordinates for the nonhydrogen atoms in the crystal structure of $3,5-\mathrm{DMBB} \quad\left[P 2_{1} / c ; \quad a=8.4497(4) \AA, \quad b=4.5123(1) \AA, c\right.$ $\left.=25.2799(1) \AA, \beta=93.743(1)^{\circ}, V=958.32(9) \AA^{3}\right]$.

\begin{tabular}{lccc}
\hline \hline Atom & $x$ & $y$ & $z$ \\
\hline Cl & $0.5593(1)$ & $-0.0076(3)$ & $0.3655(1)$ \\
C2 & $0.5141(3)$ & $0.0634(8)$ & $0.4156(1)$ \\
C3 & $0.3839(3)$ & $0.2385(7)$ & $0.4224(1)$ \\
C4 & $0.3047(2)$ & $0.3675(7)$ & $0.3774(1)$ \\
C5 & $0.3580(3)$ & $0.3153(7)$ & $0.3265(1)$ \\
C6 & $0.4850(2)$ & $0.1293(7)$ & $0.3217(1)$ \\
O7 & $0.2807(2)$ & $0.4170(4)$ & $0.2795(1)$ \\
C8 & $0.1502(1)$ & $0.6137(1)$ & $0.2827(1)$ \\
O9 & $0.3375(2)$ & $0.3274(4)$ & $0.4724(1)$ \\
C10 & $0.2033(1)$ & $0.5113(1)$ & $0.4749(1)$ \\
C11 & $0.7028(1)$ & $-0.1896(1)$ & $0.3624(1)$ \\
Br12 & $0.9006(1)$ & $-0.0014(3)$ & $0.3818(1)$ \\
\hline \hline
\end{tabular}

our genetic algorithm (GA) technique was used to search for the structure representing the global minimum in $R_{\mathrm{wp}}$ in the direct-space structure solution calculation.

In the GA technique, a population of trial structures is allowed to evolve subject to rules and operations (mating, mutation, and natural selection) analogous to those that govern evolution in biological systems. Each structure in the population is specified by its "genetic code," which represents, for each molecule in the asymmetric unit, the position $\{x, y, z\}$ and orientation $\{\theta, \varphi, \psi\}$ of the molecule in the unit cell, and the molecular conformation, defined by $n$ variable torsion angles $\left\{\tau_{1}, \tau_{2}, \ldots, \tau_{\mathrm{n}}\right\}$. The quality ("fitness") of each structure in the population is assessed from its value of $R_{\mathrm{wp}}$. New structures are generated by the mating and mutation operations. In the natural selection procedure, only the structures of highest fitness (i.e., lowest $R_{\mathrm{wp}}$ ) are allowed to pass from one generation to the next generation. In the GA structure solution calculation, the population is allowed to evolve for a specified number of generations or until convergence is reached. After the population has evolved for a sufficient number of generations, the best structure in the population (i.e., the structure with lowest $R_{\mathrm{wp}}$ ) should be close to the correct crystal structure. Details of the GA technique for structure solution (Kariuki et al., 1997; Harris et al., 1998; Habershon et al., 2003), as implemented in the current work, and examples of the application of this technique (Cheung et al., 2003; Albesa-Jové et al., 2004; Guo and Harris, 2005), are given in the references cited.

The best structure solution obtained in the GA structure solution calculation is used as the starting structural model for Rietveld refinement. To assess the quality of fit obtained in the final Rietveld refinement, an important issue is to compare the difference profile obtained in the Rietveld refinement with the difference profile obtained for the same experimental powder X-ray diffraction pattern in the patterndecomposition/profile-fitting stage of the structure determination process (i.e., from the Pawley or Le Bail fitting procedure). Clearly, the fit obtained in the patterndecomposition/profile-fitting procedure establishes a limit to the quality of fit that could be obtained in a Rietveld refinement calculation for the same experimental powder X-ray diffraction pattern (taken over the same $2 \theta$ range).
TABLE II. Selected $d$-spacings and intensities for 3,5-DMBB.

\begin{tabular}{lr}
\hline$d / \AA$ & Intensities \\
\hline 3.021 & 1864 \\
3.078 & 13134 \\
3.149 & 2085 \\
3.170 & 3264 \\
3.364 & 10585 \\
3.406 & 3167 \\
3.556 & 5461 \\
3.618 & 1359 \\
3.670 & 4358 \\
3.763 & 3148 \\
3.832 & 1970 \\
3.866 & 11260 \\
3.922 & 8378 \\
3.951 & 18760 \\
3.976 & 13203 \\
4.081 & 7875 \\
4.250 & 3162 \\
4.444 & 6826 \\
4.901 & 2711 \\
5.218 & 18384 \\
6.308 & 1368 \\
6.810 & \\
7.233 & \\
\hline
\end{tabular}

\section{EXPERIMENTAL}

Synthesis of 3,5-DMBB and 3,4,5-TMBB was carried out by bromination of the corresponding hydroxy compounds (3,5-dimethoxybenzyl alcohol and 3,4,5trimethoxybenzyl alcohol, respectively) using phosphorus tribromide at $-10^{\circ} \mathrm{C}$ in a sodium chloride ice bath. Both compounds were purified by column chromatography on silica gel, and recrystallized from hexane. Full characterization was carried out using standard techniques (solution state ${ }^{1} \mathrm{H}$ and ${ }^{13} \mathrm{C}$ NMR and mass spectrometry).

For measurement of the powder X-ray diffraction pattern of 3,5-DMBB, the sample was ground and packed between two pieces of transparent tape. The powder X-ray diffraction pattern was recorded at ambient temperature in transmission mode on a Siemens D5000 diffractometer $\left(\mathrm{Cu} K_{\alpha 1}\right.$ radiation, Ge-monochromated; linear position-sensitive detector covering $8^{\circ}$ in $2 \theta ; 2 \theta$ range $5^{\circ}$ to $70^{\circ}$; step size $0.020^{\circ}$; data collection time $15 \mathrm{~h}$ ).

For measurement of the powder X-ray diffraction pattern of 3,4,5-TMBB, the sample was ground and loaded into a borosilicate glass capillary $(0.7 \mathrm{~mm}$ diameter $)$. The powder $\mathrm{X}$-ray diffraction pattern was recorded at ambient temperature in transmission mode on a Bruker D8 diffractometer $(\mathrm{Cu}$ $K_{\alpha 1}$ radiation, Ge-monochromated; linear position-sensitive VANTEC detector covering $12^{\circ}$ in $2 \theta ; 2 \theta$ range $3^{\circ}$ to $70^{\circ}$; step size $0.017^{\circ}$; data collection time $12 \mathrm{~h}$ ).

The crystal structures of 3,5-DMBB and 3,4,5-TMBB were determined directly from the powder X-ray diffraction data using our GA technique [implemented in the program EAGER (Habershon et al., 2005)] for structure solution, and using the GSAS program (Larson and Von Dreele, 1987) for Le Bail and Rietveld refinement. 

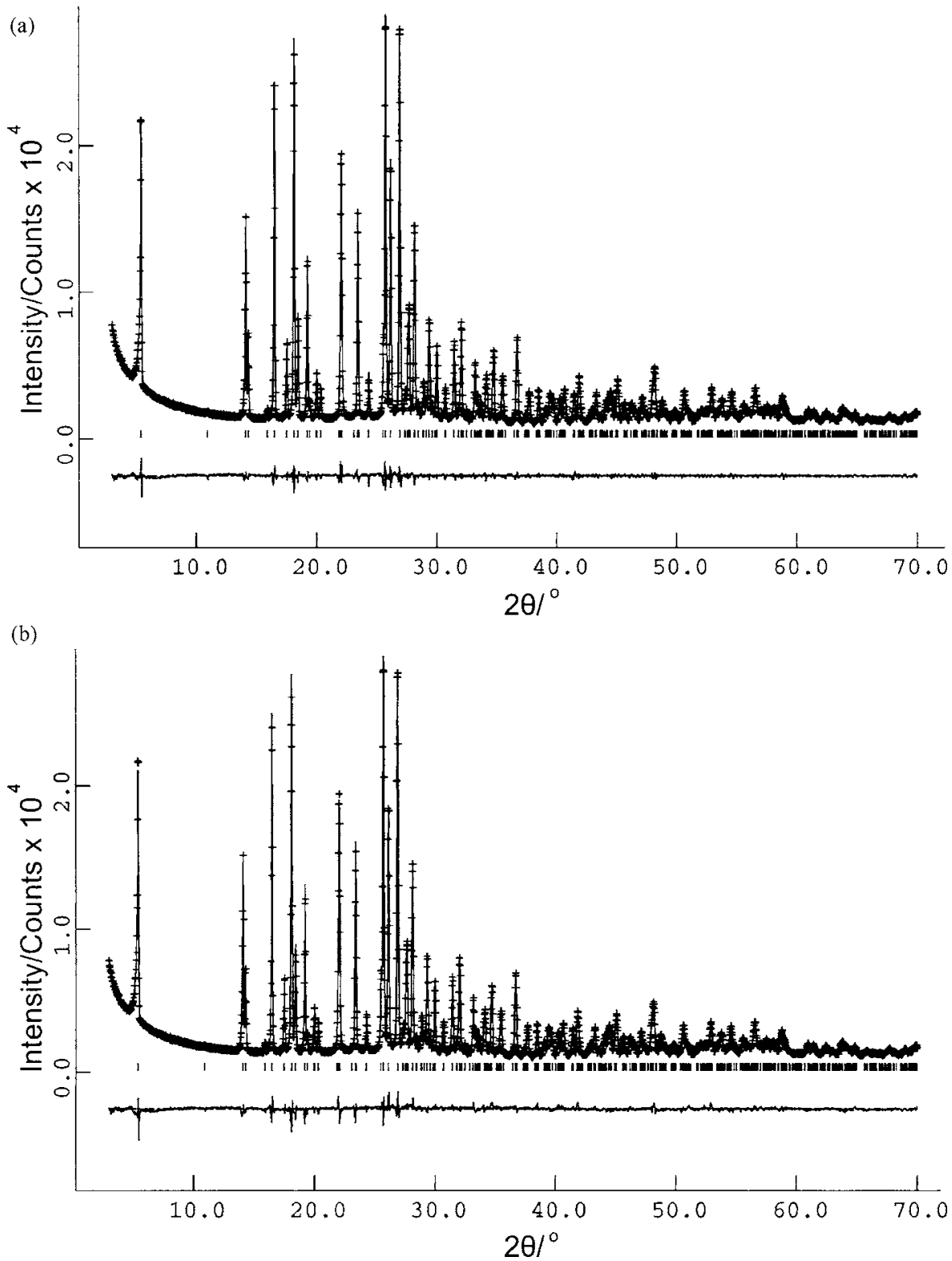

Figure 3. (a) Le Bail fit of the powder X-ray diffraction pattern for $3,4,5$ TMBB. (b) Final Rietveld refinement for 3,4,5-TMBB.

\section{STRUCTURE DETERMINATION}

\section{A. Structure determination of 3,5-DMBB}

The powder X-ray diffraction pattern of 3,5-DMBB was indexed using the program DICVOL (Boultif and Louër, 1991), leading to the following unit cell with monoclinic metric symmetry: $a=8.45 \AA, b=4.51 \AA, c=25.28 \AA, \beta$ $=93.73^{\circ}, \quad V=962.77 \AA^{3} \quad\left(M_{20}=34.0, \quad F_{20}=81.3\right)$. Patterndecomposition/profile-fitting using the Le Bail method (Le Bail et al., 1988) produced a good quality fit [Figure 2(a); $\left.R_{\mathrm{wp}}=2.75 \%, R_{p}=1.75 \%, R_{\mathrm{exp}}=3.07 \%\right]$, serving both to confirm the correctness of the unit cell and to establish suitable profile parameters for use in the subsequent structure solution calculation. On the basis of systematic absences, the space group was assigned as $P 2_{1} / c$. Density considerations suggest that there are four molecules of 3,5-DMBB in the unit cell $(Z=4)$. For space group $P 2_{1} / c$, there is therefore one molecule in the asymmetric unit $\left(Z^{\prime}=1\right)$.

For structure solution, each trial structure was defined by a total of nine structural variables: $\left\{x, y, z, \theta, \varphi, \psi, \tau_{1}, \tau_{2}, \tau_{3}\right\}$. The three variable torsion angles are indicated in Figure 1(a). The population comprised 100 trial structures, and in the evolution of the population from one generation to the next generation, 50 mating operations and 25 mutation operations were carried out. The best trial structure obtained after 15 generations in the structure solution calculation (i.e., after sampling a total of 1975 trial structures) was used as the initial structural model for Rietveld refinement. In the Rietveld refinement, bond lengths and bond angles were restrained (soft constraints) to standard values, and planar restraints were applied to the aromatic rings. Isotropic displacement parameters were refined for all nonhydrogen atoms. All hydrogen atoms, including those of the methyl groups, were placed at calculated positions with a fixed value $\left(0.05 \AA^{2}\right)$ for the isotropic displacement parameter. The Rietveld refinement led to a good quality of fit [Figure 2(b); $R_{\mathrm{wp}}=4.06 \%, R_{p}=2.89 \%$ for 3236 observations and 37 parameters; $R_{F}^{2}=8.71 \%$ for 842 observations; final refined unit cell parameters: $a=8.4497(4) \AA$, $b=4.5123(1) \AA, \quad c=25.2799(1) \AA, \quad \beta=93.743(1)^{\circ}$, 
TABLE III. Fractional coordinates for the nonhydrogen atoms in the crystal structure of $3,4,5$-TMBB $\left[P 2_{1} / c ; a=16.5165(2) \AA, b=5.31473(8) \AA, c\right.$ $\left.=12.6675(2) \AA, \beta=103.334(1)^{\circ}, V=1081.99(4) \AA^{3}\right]$.

\begin{tabular}{lccc}
\hline \hline Atom & $x$ & $y$ & $z$ \\
\hline C1 & $0.3070(2)$ & $0.2176(7)$ & $0.0984(3)$ \\
C2 & $0.3085(2)$ & $0.0554(13)$ & $0.1851(5)$ \\
C3 & $0.2388(2)$ & $0.0333(13)$ & $0.2269(6)$ \\
C4 & $0.1690(2)$ & $0.1870(9)$ & $0.1869(4)$ \\
C5 & $0.1696(2)$ & $0.3608(13)$ & $0.1023(6)$ \\
C6 & $0.2402(2)$ & $0.3806(11)$ & $0.0609(6)$ \\
O7 & $0.2309(1)$ & $-0.1360(8)$ & $0.3042(3)$ \\
C8 & $0.2979(1)$ & $-0.3059(4)$ & $0.3419(1)$ \\
O9 & $0.0959(2)$ & $0.1570(7)$ & $0.2232(3)$ \\
C10 & $0.0825(1)$ & $0.3477(3)$ & $0.2941(1)$ \\
O11 & $0.0983(1)$ & $0.4943(9)$ & $0.0647(3)$ \\
C12 & $0.0984(1)$ & $0.6869(4)$ & $-0.0152(1)$ \\
\hline \hline
\end{tabular}

$\left.V=958.32(9) \AA^{3}\right]$. Fractional atomic coordinates in the final refined crystal structure are given in Table I and $d$-spacings and intensities are listed in Table II.

\section{B. Structure determination of 3,4,5-TMBB}

The powder X-ray diffraction pattern of 3,4,5-TMBB was indexed using the program DICVOL, leading to the following unit cell with monoclinic metric symmetry: $a=16.52 \AA, \quad b=5.31 \AA, \quad c=12.66 \AA, \quad \beta=103.29^{\circ}$, $V=1081.27 \AA^{3} \quad\left(M_{20}=44.6, \quad F_{20}=99.6\right) . \quad$ Patterndecomposition/profile-fitting using the Le Bail method produced a good quality fit [Figure 3(a); $R_{\mathrm{wp}}=4.29 \%, R_{p}$ $\left.=3.23 \%, R_{\exp }=1.99 \%\right]$. On the basis of systematic absences, the space group was assigned as $P 2_{1} / c(Z=4)$, and density considerations suggest that there is one molecule of 3,4,5TMBB in the asymmetric unit $\left(Z^{\prime}=1\right)$.

For structure solution, each trial structure was defined by a total of ten structural variables: $\left\{x, y, z, \theta, \varphi, \psi, \tau_{1}, \tau_{2}, \tau_{3}, \tau_{4}\right\}$. The four variable torsion angles are indicated in Figure 1(b). The population comprised 100 trial structures, and in the evolution of the population from one generation to the next generation, 50 mating operations and 25 mutation operations were carried out. The best trial structure obtained after 20 generations in the structure solution calculation (i.e., after sampling a total of 2600 trial structures) was used as the initial structural model for Rietveld refinement, which was carried out using the general procedure discussed in Sec. IV A. The Rietveld refinement led to a good quality of fit [Figure 3(b); $R_{\mathrm{wp}}=4.97 \%, R_{p}$ $=3.93 \%$ for 3987 observations and 43 parameters; $R_{F}^{2}$ $=6.46 \%$ for 944 observations; final refined unit cell parameters: $a=16.5165(2) \AA, b=5.31473(8) \AA, c=12.6675(2) \AA$, $\left.\beta=103.334(1)^{\circ}, V=1081.99(4) \AA^{3}\right]$. Fractional atomic coordinates in the final refined crystal structure are given in Table III and $d$-spacings and intensities are listed in Table IV.

\section{DISCUSSION}

\section{A. Crystal structure of 3,5-DMBB}

The conformation adopted by the 3,5-DMBB molecule in the crystal structure is shown in Figure 4(a). The bromine
TABLE IV. Selected $d$-spacings and intensities for 3,4,5-TMBB.

\begin{tabular}{lr}
\hline$d / \AA$ & Intensities \\
\hline 3.168 & 1304 \\
3.222 & 861 \\
3.308 & 2855 \\
3.405 & 1497 \\
3.460 & 2227 \\
3.651 & 425 \\
3.790 & 1553 \\
4.021 & 1872 \\
4.355 & 381 \\
4.428 & 473 \\
4.605 & 1261 \\
4.797 & 852 \\
4.884 & 2886 \\
5.051 & 690 \\
5.361 & 2298 \\
6.169 & 657 \\
6.261 & 1508 \\
\hline \hline
\end{tabular}

atom of the $\mathrm{CH}_{2} \mathrm{Br}$ group lies out of the plane of the phenyl ring, and the two $\mathrm{O}-\mathrm{CH}_{3}$ bonds lie close to the plane of the phenyl ring and are oriented parallel to each other in a syn, syn conformation [the designations syn and anti refer to the orientations of the $\mathrm{C}(3) \mathrm{O}-\mathrm{CH}_{3}$ and $\mathrm{C}(5) \mathrm{O}-\mathrm{CH}_{3}$ bonds relative to the orientation of the $\mathrm{C}(4)-\mathrm{H}$ bond]. With regard to this feature, other molecules containing 3,5dimethoxyphenyl rings (with hydrogen atoms in the 2-, 4-, and 6-positions) display a range of different conformations, including other examples with syn,syn conformations (Lin et al., 1979; Bartholomew et al., 2000), examples of syn,anti conformations (Lynch et al., 1994; Peters et al., 1993; Pettit et al., 1988), an example with two independent molecules in the asymmetric unit with anti,anti and syn,anti conformations (Yin et al., 2002), and an example with two independent 3,5-dimethoxyphenyl moieties in a given molecule that adopt syn,syn and syn,anti conformations (Yin and Zhang, 2002).

In the crystal structure [Figure 4(b)], the 3,5-DMBB molecules are stacked along the $b$-axis, with adjacent molecules along the stack related to each other by the unit cell translation. Thus, the planes of the phenyl ring of the molecules in the stack are parallel to each other, but there are no significant $\pi \cdots \pi$ stacking interactions between adjacent molecules as a consequence of the tilting of the planes of the phenyl rings relative to the stacking axis. Along the $c$-axis [horizontal in Figure 4(b)], there are rows of molecules with relatively short $\mathrm{C}-\mathrm{H} \cdots \mathrm{O}$ contacts between the $\mathrm{C}-\mathrm{H}$ bonds of the phenyl ring of one molecule and methoxy groups of neighbouring molecules. Along these rows, pairs of adjacent molecules $(A \cdots A)$ lie in the same plane as each other (and are related across an inversion centre, denoted by the symbol - ), whereas the next pair of adjacent molecules $(B \cdots B)$ again lie in the same plane as each other (and are related across an inversion centre), but with the planes of the $A$ and $B$ molecules almost perpendicular to each other. The overall arrangement along these rows is thus $\cdots A \cdots A \cdots B \cdots B \cdots A \cdots A \cdots B \cdots B \cdots$ [Figure 4(c)]. Thus, the structure does not comprise planar sheets of molecules. 

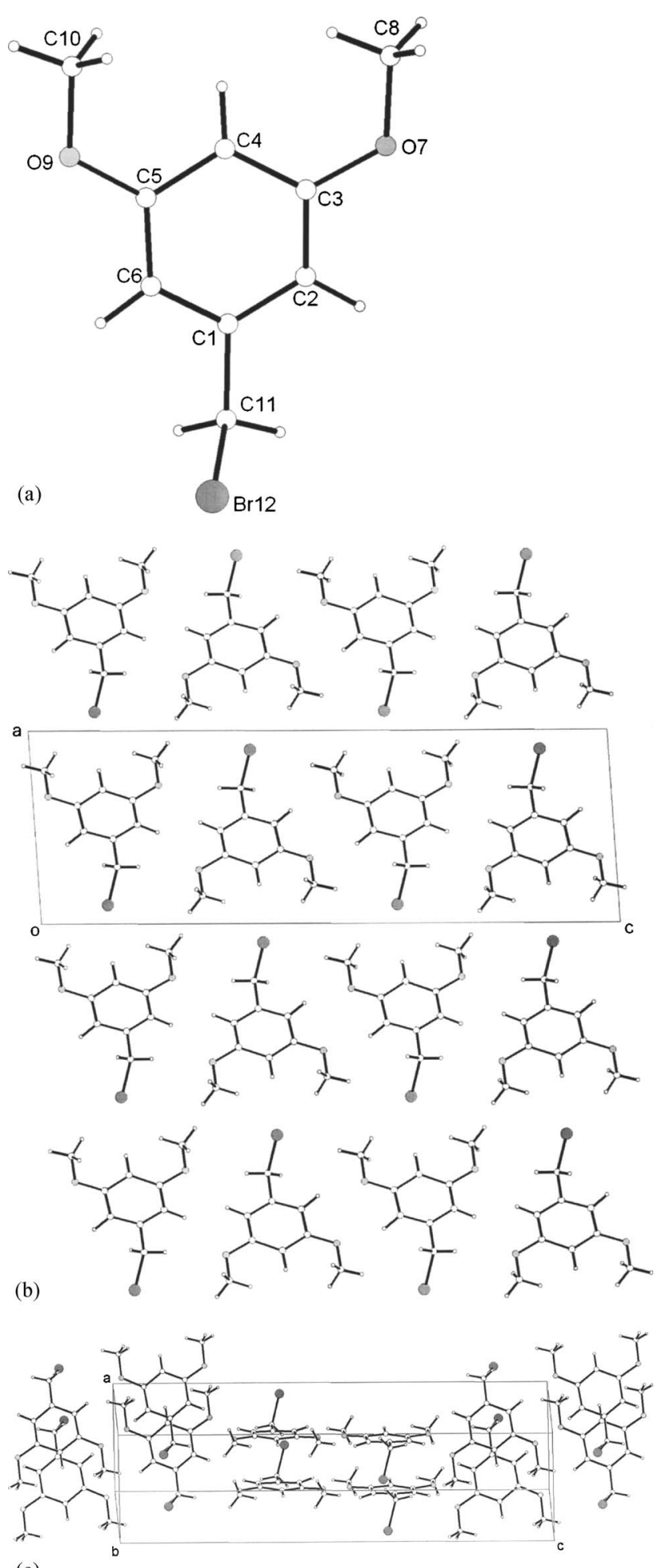

(c)

Figure 4. (a) The conformation adopted by 3,5-DMBB in its crystal structure. (b) Crystal structure of 3,5-DMBB viewed along the $b$-axis. (c) Part of the crystal structure of 3,5-DMBB showing two rows of molecules along the $c$-axis (horizontal), with these rows of molecules stacked along the $b$-axis (into the plane of the page).

Rather, when viewed along the $c$-axis, there are two orientations of the molecular planes that are almost perpendicular to each other. The rows of molecules (along the $c$-axis) are stacked along the $b$-axis as discussed above, leading to slabs of molecules parallel to the $b c$-plane. At the interface be-
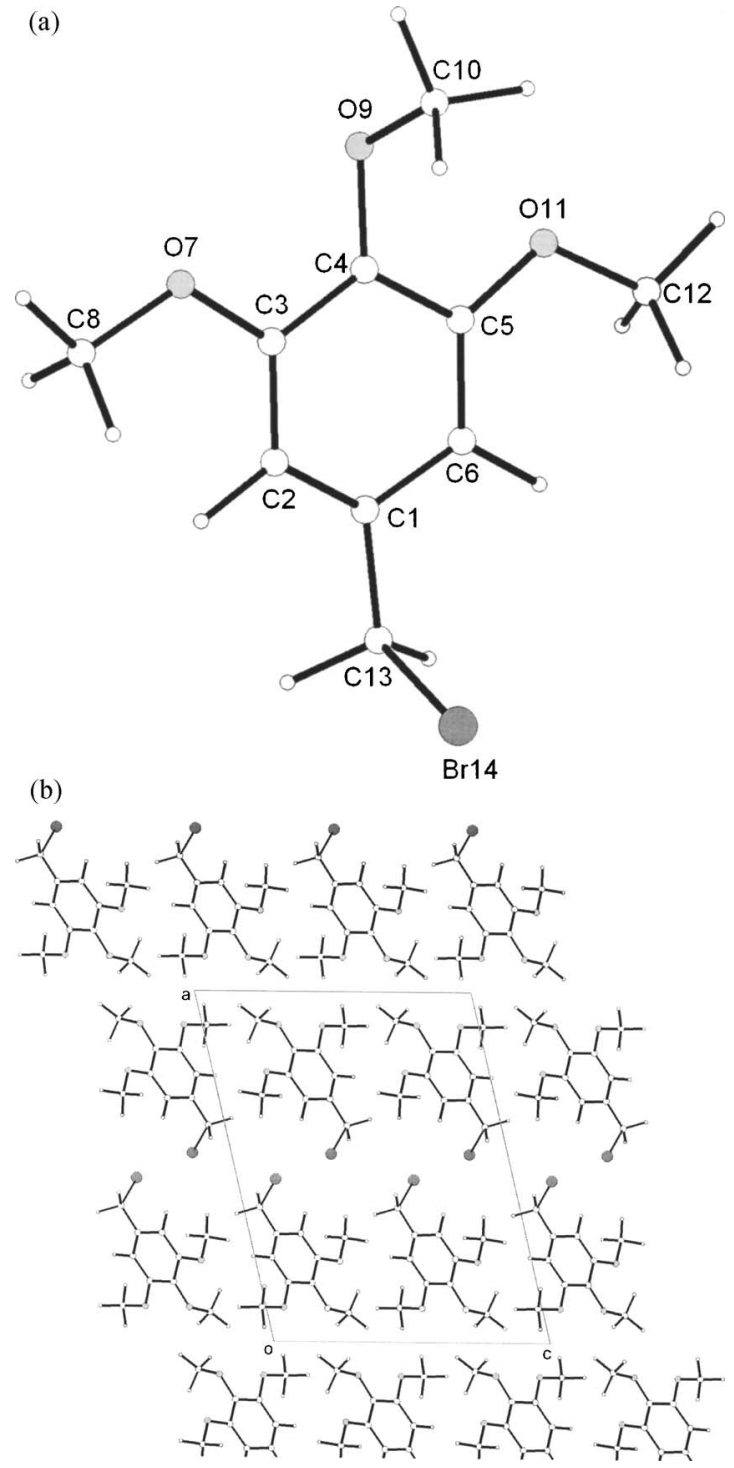

Figure 5. (a) The conformation adopted by $3,4,5-\mathrm{TMBB}$ in its crystal structure. (b) Crystal structure of 3,4,5-TMBB viewed along the $b$-axis.

tween adjacent slabs of this type, the bromine atoms of one molecule come into van der Waals contact with the two methyl (methoxy) groups of a neighbouring molecule (as discussed below, this feature contrasts with the structure of 3,4,5-TMBB).

\section{B. Crystal structure of 3,4,5-TMBB}

The conformation adopted by the 3,4,5-TMBB molecule in the crystal structure is shown in Figure 5(a). The methoxy groups at the 3- and 5-positions lie close to the plane of the phenyl ring, and the $\mathrm{C}(3) \mathrm{O}-\mathrm{CH}_{3}$ and $\mathrm{C}(5) \mathrm{O}-\mathrm{CH}_{3}$ bonds are oriented away from each other in an anti,anti conformation [the designations syn and anti refer to the orientations of the $\mathrm{C}(3) \mathrm{O}-\mathrm{CH}_{3}$ and $\mathrm{C}(5) \mathrm{O}-\mathrm{CH}_{3}$ bonds relative to the orientation of the $\mathrm{C}(4)-\mathrm{O}$ bond]. For the methoxy group at the 4-position, on the other hand, the methyl group lies out of the plane of the phenyl ring, with the $\mathrm{C}(4) \mathrm{O}-\mathrm{CH}_{3}$ bond pointing almost perpendicular to the plane of the ring. These conformational features are commonly observed in crystal struc- 
tures of other molecules containing 3,4,5-trimethoxyphenyl rings (with hydrogen atoms in the 2- and 6-positions) (Saad et al., 1991; Wallet et al., 1995; Lockhart et al., 1987; Krygowski et al., 2001). In contrast to the conformational properties discussed above for 3,5-dimethoxyphenyl rings, as found in 3,5-DMBB, it is apparent that there is much less latitude for conformational variation in 3,4,5trimethoxyphenyl rings. In the 3,4,5-TMBB molecule, the bromine atom of the $\mathrm{CH}_{2} \mathrm{Br}$ group also lies out of the plane of the phenyl ring, and is oriented outwards from the same face of the phenyl ring as the methoxy group at the 4-position.

In the crystal structure [Figure 5(b)], the 3,4,5-TMBB molecules are stacked along the $b$-axis, with adjacent molecules along the stack related to each other by the unit cell translation. The planes of the phenyl rings of the molecules in the stack are parallel to each other, but there are no significant $\pi \cdots \pi$ stacking interactions between adjacent molecules as a consequence of the tilting of the planes of the phenyl rings relative to the stacking axis. Along the $c$-axis [horizontal in Figure 5(b)], there are zigzag rows of molecules with relatively short $\mathrm{C}-\mathrm{H} \cdots \mathrm{O}$ contacts between the $\mathrm{C}-\mathrm{H}$ bonds of the phenyl rings of one molecule and the methoxy groups of the neighbouring molecules; along these rows, the molecules alternate between two different orientations (leading to the description as a zigzag row). These rows of molecules (along the $c$-axis) are stacked along the $b$-axis as discussed above, leading to slabs of molecules parallel to the $b c$-plane. The two surfaces of the slab are different from each other-one surface (the "bromine surface") contains the bromine atoms of all molecules in the slab, whereas the other surface (the "methoxy surface") contains two methoxy groups from each molecule in the slab (the other methoxy group of each molecule lies within the slab). These slabs are stacked along the $a$-axis, and within the unit cell there are two different types of interface (parallel to the $b c$-plane) between adjacent slabs. At one interface, the bromine surfaces of adjacent slabs are in van der Waals contact with each other, whereas at the other interface, the methoxy surfaces of adjacent slabs are in van der Waals contact with each other. In contrast, in the structure of 3,5-DMBB discussed above, the two surfaces of a slab of molecules are equivalent by symmetry (and each surface contains both bromine and methoxy groups), and all interfaces between adjacent slabs are also equivalent by symmetry.

\section{ACKNOWLEDGMENTS}

We are grateful to EPSRC for general support (to K.D.M.H.) and to Bruker AXS and the University of Birmingham for the award of a studentship (to Z.P.).

Albesa-Jové, D., Kariuki, B. M., Kitchin, S. J., Grice, L., Cheung, E. Y., and Harris, K. D. M. (2004). "Challenges in direct-space structure determination from powder diffraction data: A molecular material with four independent molecules in the asymmetric unit," ChemPhysChem 5, $414-418$.

Altomare, A., Caliandro, R., Camalli, M., Cuocci, C., Giacovazzo, C., Moliterni, A. G. G., Rizzi, R., Spagna, R., and Gonzalez-Platas, J. (2004). "Towards EXPO2005," Z. Kristallogr. 216, 833-837.

Bartholomew, G. P., Bazan, G. C., Bu, X. H., and Lachicotte, R. J. (2000). "Packing modes of distyrylbenzene derivatives," Chem. Mater. 12, 1422-1430.
Boultif, A. and Louër, D. (1991). "Indexing of powder diffraction patterns for low-symmetry lattices by the successive dichotomy method," J. Appl. Crystallogr. 24, 987-993.

Boultif, A. and Louër, D. (2004). "Powder pattern indexing with the dichotomy method," J. Appl. Crystallogr. 37, 724-731.

Chernyshev, V. V. (2001). "Structure determination from powder diffraction," Russ. Chem. Bull. 50, 2273-2292.

Cheung, E. Y., Kitchin, S. J., Harris, K. D. M., Imai, Y., Tajima, N., and Kuroda, R. (2003). "Direct structure determination of a multi-component molecular crystal prepared by a solid state grinding procedure," J. Am. Chem. Soc. 125, 14658-14659.

Favre-Nicolin, V. and Černý, R. (2004). "A better Fox: Using flexible modeling and maximum likelihood to improve direct-space ab initio structure determination from powder diffraction," Z. Kristallogr. 216, 847856.

Giovannini, J., Ceolin, R., Perrin, M. A., Toscani, S., Louër, D., and Leveiller, F. (2001a). "Polymorphism and hydration of zopiclone: Determination of crystal structures, and thermodynamic studies as a function of temperature and water vapor pressure," J. Phys. IV 11, 93-97.

Giovannini, J., Ter Minassian, L., Ceolin, R., Toscani, S., Perrin, M. A., Louër, D., and Leveiller, F. (2001b). "Tetramorphism of fananserine: p, $\mathrm{T}$ diagram and stability hierarchy from crystal structure determinations and thermodynamic studies," J. Phys. IV 11, 123-126.

Guo, F. and Harris, K. D. M. (2005). "Structural understanding of a molecular material that is accessed only by a solid-state desolvation process: The scope of modern powder X-ray diffraction techniques," J. Am. Chem. Soc. 127, 7314-7315.

Habershon, S., Harris, K. D. M., and Johnston, R. L. (2003). "Development of a multi-population parallel genetic algorithm for structure solution from powder diffraction data," J. Comput. Chem. 24, 1766-1774.

Habershon, S., Turner, G. W., Kariuki, B. M., Cheung, E. Y., Hanson, A. J., Tedesco, E., Albesa-Jové, D., Chao, M.-H., Lanning, O. J., Johnston, R. L., and Harris, K. D. M. (2005). EAGER-A Computer Program for Direct-Space Structure Solution from Powder X-ray Diffraction Data, Cardiff University and University of Birmingham.

Harris, K. D. M. and Cheung, E. Y. (2004). "How to determine structures when single crystals cannot be grown: Opportunities for structure determination of molecular materials using powder diffraction data," Chem. Soc. Rev. 33, 526-538.

Harris, K. D. M. and Tremayne, M. (1996). "Crystal structure determination from powder diffraction data," Chem. Mater. 8, 2554-2570.

Harris, K. D. M., Johnston, R. L., and Kariuki, B. M. (1998). "The genetic algorithm: Foundations and applications in structure solution from powder diffraction data," Acta Crystallogr., Sect. A: Found. Crystallogr. 54, 632-645.

Harris, K. D. M., Tremayne, M., and Kariuki, B. M. (2001). "Contemporary advances in the use of powder X-ray diffraction for structure determination," Angew. Chem., Int. Ed. 40, 1626-1651.

Harris, K. D. M., Tremayne, M., Lightfoot, P., and Bruce, P. G. (1994). "Crystal structure determination from powder diffraction data by Monte Carlo methods," J. Am. Chem. Soc. 116, 3543-3547.

Kariuki, B. M., Serrano-González, H., Johnston, R. L., and Harris, K. D. M. (1997). "The application of a genetic algorithm for solving crystal structures from powder diffraction data," Chem. Phys. Lett. 280, 189-195.

Krygowski, T. M., Pindelska, E., Anulewicz-Ostrowska, T., Grabowski, S. J., and Dubis, A. T. (2001). "Angular group-induced bond alternation (AGIBA). Conformation dependence and additivity of the effect: Structural studies of 3,5-dimethoxybenzaldehyde derivatives and related systems," J. Phys. Org. Chem. 14, 349-354.

Langford, J. I. and Louër, D. (1996). "Powder diffraction," Rep. Prog. Phys. $\mathbf{5 9}, 131-234$

Langford, J. I., Louër, D., and Scardi, P. (2000). "Effect of a crystallite size distribution on X-ray diffraction line profiles and whole-powder-pattern fitting," J. Appl. Crystallogr. 33, 964-974.

Larson, A. C., and Von Dreele, R. B. (1987). GSAS, Los Alamos Laboratory Report No. LA-UR-86-748.

Le Bail, A., Duroy, H., and Fourquet, J. L. (1988). "Ab initio structure determination of $\mathrm{LiSbWO}_{6}$ by X-ray powder diffraction," Mater. Res. Bull. 23, 447-452.

Lin, Y., Lang, S. A., Lovell, M. F., and Perkinson, N. A. (1979). "New synthesis of 1,2,4-triazoles and 1,2,4-oxadiazoles," Org. Chem. 44, 4160-4164.

Lockhart, J. C., McDonnell, M. B., Clegg, W., and Hill, M. N. S. (1987). "Structure and dynamics of crowns containing the phenyldinaphthylmethane subunit (a three-bladed propeller): Observations of correlated 
rotation of the propeller blades and certain ether segments," J. Chem. Soc., Perkin Trans. 1 2, 639-649.

Louër, D. (1988). "Some recent developments and applications of powder diffraction," Chem. Scr. 28, 89-95.

Louër, D. (1996). "Powder X-ray diffraction 100 years after Roentgen," J. Phys. IV 6, 57-69.

Louër, D. (1998). "Advances in powder diffraction analysis," Acta Crystallogr., Sect. A: Found. Crystallogr. 54, 922-933.

Louër, D. (2003). "Microstructure and profile of X-ray diffraction lines," J. Phys. IV 103, 321-337.

Louër, D. and Louër, M. (1972). "Trial-and-error method for automatic indexing of powder diagrams," J. Appl. Crystallogr. 5, 271-275.

Lynch, D. E., Smith, G., Byriel, K. A., and Kennard, C. H. L. (1994). "3,5-Dimethoxybenzoic acid and the second polymorph of the 2:1 adduct of 3,5-dinitrobenzoic acid with ethylenediamine," Acta Crystallogr., Sect. C: Cryst. Struct. Commun. 50, 1259-1262.

McCusker, L. B., Von Dreele, R. B., Cox, D. E., Louër, D., and Scardi, P. (1999). "Rietveld refinement guidelines," J. Appl. Crystallogr. 32, 3650.

Pan, Z., Cheung, E. Y., Harris, K. D. M., Constable, E. C., and Housecroft, C. E. (2004). "Structural aspects of a dendrimer precursor determined directly from powder diffraction data," Cryst. Growth Des. 4, 451-455.

Pawley, G. S. (1981). "Unit-cell refinement from powder diffraction scans," J. Appl. Crystallogr. 14, 357-361.

Peters, K., Peters, E.-M., von Schnering, H. G., Bringmann, G., and Rolfing,
K. (1993). "Crystal structure of (E)-1-(1-bromo-2-naphthyl)-2(3,5-dimethoxyphenyl)ethane," Z. Kristallogr. 207, 125-127.

Pettit, G. R., Singh, S. B., Schmidt, J. M., Niven, M. L., Hamel, E., and Lin, C. M. (1988). "Isolation, structure, synthesis, and antimitotic properties of combretastatins B-3 and B-4 from combretum caffrum," J. Nat. Prod. 51, 517-527.

Rietveld, H. M. (1969). "A profile refinement method for nuclear and magnetic structures,” J. Appl. Crystallogr. 2, 65-71.

Saad, J. M., Soepadamo, E., Fang, X.-P., McLaughlin, J. L., and Fanwick, P. E. (1991). "(-)-Grandisin from cryptocarya crassinervia," J. Nat. Prod. 54, 1681-1683.

Shankland, K., Markvardsen, A. J., and David, W. I. F. (2004). "Powder diffraction based structural studies of pharmaceuticals," Z. Kristallogr. 216, 857-865.

Wallet, J. C., Molins, E., and Miravitlles, C. (1995). "1-Phenyl-3-(3,4,5trimethoxyphenyl)-1,3-propanedione," Acta Crystallogr., Sect. C: Cryst. Struct. Commun. 51, 103-104.

Yin, Q. and Zhang, W. Q. (2002). "1-(3,5-Dimethoxyphenyl)-2-\{2-[(3,5dimethoxyphenyl)hydroxymethyl]-4-methoxyphenyl\}ethanol," Acta Crystallogr., Sect. E: Struct. Rep. Online 58, 1367-1369.

Yin, Q., Shi, Y.-M., Liu, H.-M., Li, C.-B., and Zhang, W. Q. (2002). “(E)-3,5,4' -Trimethoxystilbene,” Acta Crystallogr., Sect. E: Struct. Rep. Online 58, 1180-1181.

Young, R. A., Editor. (1993). The Rietveld Method (International Union of Crystallography, Oxford). 